\title{
Determination of the Interfacial Heat Transfer Coefficient in the Hot Stamping of AA7075
}

\author{
Kang Ji, Xiaochuan Liu, Omer El Fakir, Jun Liu, Qunli Zhang, and Liliang Wang* \\ Department of Mechanical Engineering, Imperial College London, SW7 2AZ, UK
}

Received 1 October 2015 / Accepted 4 September 2016

\begin{abstract}
The interfacial heat transfer coefficient (IHTC) is a key parameter in hot stamping processes, in which a hot blank is formed and quenched by cold dies simultaneously. The IHTC should therefore be identified and used in FE simulations to improve the accuracy of simulation results of hot stamping processes. In this work, a hot stamping simulator was designed and assembled in a Gleeble 3800 thermo-mechanical testing system and a FE model was built in PAM-STAMP to determine the IHTC values between a hot aluminium alloy 7075 blank and cold dies. The IHTC values were determined at different contact pressures under both dry and lubricated (Omega-35) conditions. In addition, a model to calculate the IHTC value at different contact pressures and area densities of lubricant was developed for the hot stamping process, which was proved to be working well with verification tests.
\end{abstract}

Key words: Aluminium alloys, Hot stamping, Heat transfer, AA7075, FE simulation

\section{Introduction}

Recently, solution Heat treatment, cold die Forming and in-die Quenching, i.e. the $\mathrm{HFQ}^{1}$ process, has been developed to manufacture complex-shaped components from aluminium alloys sheets [1-4]. The hot blank is formed and quenched simultaneously by cold dies at a high forming speed. The interfacial heat transfer coefficient (IHTC), an extremely important parameter for hot/warm stamping processes, should therefore be identified not only to optimise the production rate and to achieve the critical quenching rates for different aluminium alloys, but also to retain the full mechanical strength of formed components [5].

In the past years, a number of experimental methods have been used to measure interfacial temperature evolutions and to determine IHTC values. In Bai et al.'s [6] experiments, the workpiece was placed between the lower and the upper dies, which were fixed on a hydraulic press machine and heated using a band heater. Once the target temperature was reached, the workpiece was compressed between the dies to a target pressure while the temperatures measured using thermocouples embedded in the workpiece were recorded to obtain the temperature evolutions. Some researchers [7-10] calculated IHTC values using similar methods by clamping the workpiece between two dies and measuring the temperature history of the

\footnotetext{
*e-mail: liliang.wang@imperial.ac.uk

${ }^{1} \mathrm{HFQ}^{\circledR}$ is a registered trademark of Impression Technologies Ltd.
}

workpiece as well. Alternatively, some other researchers [11-13] measured the die temperature, instead of the workpiece temperature, to obtain IHTC values. In Yukawa et al.'s [14] experiments, specimens were heated to target temperatures of $820,930,1030$ or $1180{ }^{\circ} \mathrm{C}$ and soaked for different period of times. The specimens were then moved onto a heat insulating lower die (made from Zirconia) and compressed by a heat conducting punch. The temperature evolutions of the punch were measured and recorded using thermocouples embedded into the punch at a distance of $0.5 \mathrm{~mm}$ from the contact interface. Malinowski et al. [15] and Lenard and Davies [16] measured the heat transfer between a pre-heated die and another die connected to water-cooled heat exchangers using a hydraulic press to obtain the IHTC value of the die material.

It has been widely accepted that the IHTC increases with increasing contact pressure. However, the increasing trend of the IHTC depends on the blank and die materials and processing parameters. Bai et al. [6] found that the IHTC values between a Ti-6Al-4V workpiece and a die increased with increasing contact pressures, following an exponential trend. The IHTC value increased considerably from 0.55 to $5.8 \mathrm{~kW} / \mathrm{m}^{2} \mathrm{~K}$ when the contact pressure increased from 10 to $100 \mathrm{MPa}$, and then gently increased to $6 \mathrm{~kW} / \mathrm{m}^{2} \mathrm{~K}$ when the pressure was higher than $100 \mathrm{MPa}$. The reason for this phenomenon is that the real contact area between the workpiece and dies increased significantly at the initial stage of loading, which led to the remarkable IHTC increase. 
When the pressure reached $100 \mathrm{MPa}$, the real contact area was close to the apparent contact area, and thus the IHTC approached the maximum value. The results of exponentially increasing trends of IHTC with contact pressure were also observed from the study of Jain [7] and Yukawa et al. [14] for hot forging of aluminium alloys and carbon steel. According to their research, the IHTC values can be estimated from the contact pressure using equation (1):

$$
h=a \times(1-\exp (-b \times P))
$$

where $h$ is the IHTC, $P$ is the contact pressure, and $a$ and $b$ are model constants determined by a least squares method using the experimental results.

Differing from the results above, $\mathrm{Hu}$ et al. [11] obtained a linear growth of the IHTC when the contact pressure increased between the workpiece made from B1500HS and the dies made from H11 steels in hot stamping. The IHTC increased from 4 to $6.3 \mathrm{~kW} / \mathrm{m}^{2} \mathrm{~K}$ as the contact pressure increased from 8 to $42 \mathrm{MPa}$. A similar linear increase of the IHTC with pressure was also obtained in the hot stamping of $22 \mathrm{MnB} 5$ [1] steel and hot forming of AA5083 [10].

Jain [7] studied the effect of lubricants on IHTC using aluminium alloys with different types of lubricants applied. Under the lubricated condition using $\mathrm{MoS}_{2}$, the IHTC value was higher than that under the dry condition for the same contact pressure lower than yield point. It was concluded from the results that the effect of lubricant on the IHTC depended on the lubricant chemistry and the changes of it with temperature. Burte et al. [17] presented a different result where the peak value of the IHTC under the lubricated condition was slightly lower than that under the dry condition using AA2024 as the workpiece material and graphite in water suspension as the lubricant. Bai et al. [6] had also obtained a decreasing trend in the IHTC when using a glass lubricant with a Ti-6Al-4V workpiece.

In the present research, a hot stamping simulator developed by Ji et al. [18] has been used to determine the IHTC values for a hot stamping process, under both dry and lubricated conditions. An empirical model was then developed to predict the evolutions of the IHTC values as a function of contact pressure and lubricant thickness.

\section{Experiments and FE simulation}

\subsection{Setup of the hot stamping simulator and test procedure}

A hot stamping simulator shown in Figure 1a, designed and manufactured by Ji et al. [18], was integrated into the Gleeble 3800 thermo-mechanical simulator. The present work employed an inverse technique to determine the IHTC by recording the temperature history of a $2 \mathrm{~mm}$ thick workpiece (No. 6 in Figure 1a) compressed by two $60 \mathrm{~mm}$ diameter cylindrical shaped cold dies (No. 3 in Figure 1a) which temperature was also recorded. The workpiece was made from AA7075 sheet with an average surface roughness of $0.276 \mu \mathrm{m}$, while the dies were made from mild steel with an average surface roughness of $0.437 \mu \mathrm{m}$. The workpiece holders were made from mild steel as well and the workpiece was attached to the workpiece holders with screws which were always tightened using a torque wrench, to guarantee that the tightness level was constant in every experiment.

To represent the features of a hot stamping process, the workpiece was heated to $490{ }^{\circ} \mathrm{C}$ prior to compression and the die temperature was maintained at $30^{\circ} \mathrm{C}$. As shown in Figure 1a, the workpiece was held by a workpiece holder, which was connected with two copper wires to the Gleeble. These wires provided the electric current required to heat up the specimen. Once the target temperature was reached, the specimen, which was able to move along the sliding bearing, was compressed between the two dies at different pre-defined contact pressures under either dry or lubricated conditions, with the temperature histories recorded. The temperature of dies was also recorded at the central point of the circle which was $1.5 \mathrm{~mm}$ away from the contact surface. The contact pressures were set by controlling the compressive force that was exerted by the loading arm of the Gleeble, measured by a load cell, and the temperature history was recorded by a pair of thermocouples embedded into the central point of the specimen. The lubricant used in these experiments was Omega-35 Hi-Temp MSL Grease produced by Sovereign Lubricants (UK) Ltd. Prior to each test for the lubricated condition studies, the lubricant was applied with great care onto the tool surfaces only, i.e. on both anvils, which were thoroughly cleaned by using a chemical etchant after each test. The amount of lubricant applied was precisely controlled by using dedicated equipment. Since the heat capacity of aluminium alloy is much lower than that of mild steel and the specimen was also much thinner than the dies, the changes in the die temperature were very limited during the hot stamping process. Therefore, the temperature history curves of dies were only used to ensure that the simulation results were correct, and the curves of workpiece were mainly used to determine the IHTC values. Known from previous experiences, the die closing pressure in hot stamping of aluminium sheet alloys is normally lower than $20 \mathrm{MPa}$, thus a pressure of $50 \mathrm{MPa}$ was set as an upper test limit and the pressures below $20 \mathrm{MPa}$ were mainly focused in this study.

\subsection{FE simulation setup}

As shown in Figure 1b, an FE model was built in the commercial FE software PAM-STAMP, which had the same dimensions as those of the hot stamping simulator shown in Figure 1a, the same process parameters as the experiments and the same material properties which were provided by the material suppliers, databases and literatures, to simulate temperature evolutions with various IHTC values, for comparison with the experimental temperature evolutions. The initial temperatures of the workpiece and die/punch were assigned to be $490{ }^{\circ} \mathrm{C}$ and $30{ }^{\circ} \mathrm{C}$ respectively.

A constant IHTC value was assigned for each simulation, to obtain the temperature changes of the workpiece regardless of the load and friction. The temperature histories of nodal points, located where the thermocouples were embedded in the experiments for both specimen and dies, were plotted. The temperature history curve recorded from each experimental condition was compared with the series of $\mathrm{FE}$ 
(a)

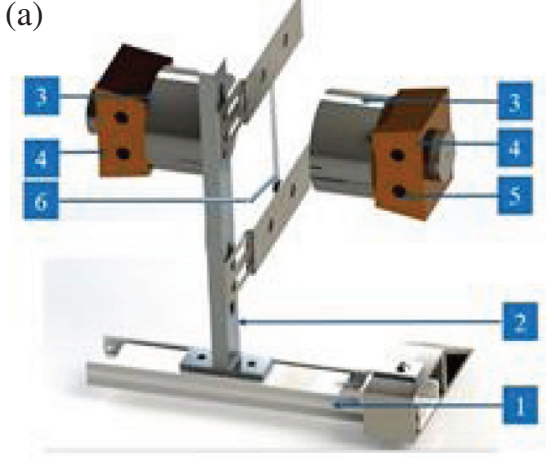

1 Sliding bearing
2 Workpiece holder
3 Anvils (dies)
4 Anvil grips

5 Power supply holes

6 Workpiece

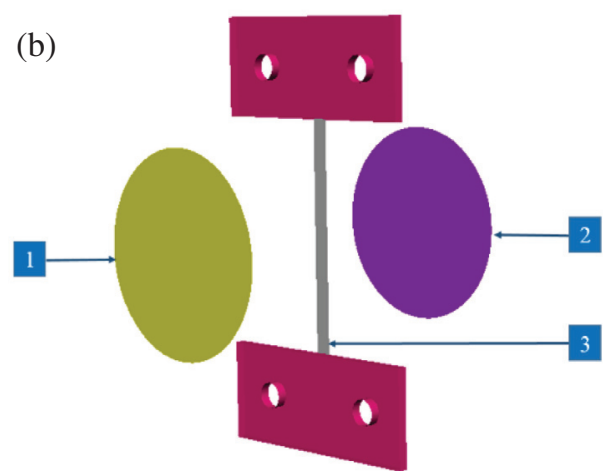

1 Die 2 Punch 3 Blank

Figure 1. (a) The hot stamping simulator [18]; (b) FE model in PAM-STAMP.

simulated curves generated by assigning different IHTC values, and the one showing the best fit to the experimental data was identified as the IHTC value under such experimental conditions.

\subsection{FE simulation setup calibration}

Simulation setup parameters has been calibrated to ensure the accuracy of the prediction results. Firstly, the workpiece temperature dropping from $490{ }^{\circ} \mathrm{C}$ to room temperature in the air has been recorded to determine the heat convection coefficient of the hot workpiece. The coefficient value was then implemented into the FE simulation so as to predict the temperature profiles numerically under the same condition with the experiment. By comparing the temperature evolution, the coefficient was further calibrated finely to build a good agreement between the simulation and experiment.

Secondly, the workpiece was assembled on the workpiece holder, see Figure 1a, and there was no contact between the workpiece and the dies. In the case, the heat transfer coefficient between the workpiece and the holder was calculated according to the changes of the workpiece temperature under such condition. In order to calibrate the heat transfer coefficient between the workpiece and the holder, FE simulation has been also established and subsequently compared with the experimental measurements.

Finally, the dies were moved in contact with the workpiece at controllable pressure conditions. The experiments under zero contact pressure, low contact pressure and high contact pressure were conducted to confirm that, with all the parameters and material properties mentioned above, the temperature histories of the dies always show good agreements with the FE simulations when the simulated temperature curves of the specimen match well with the experiment. All above done, the tests were carried out with confidence of a high accuracy FE model setup. However, since some of the material properties implemented in the FE simulation were not available from the supplier and were generated from other databases and literatures, the accuracy could be further improved by using more accurate material property values.

\section{Results and discussion}

\subsection{An empirical model for IHTC prediction}

In the present research, an empirical model has been developed, to calculate the IHTC values as a function of the contact pressure and area density of lubricant Omega-35.

$$
\begin{aligned}
h\left(P, \rho_{A}\right)= & 3.72 \times(1.21-\exp (-0.25 \times P+2.21)) \\
& +7.33 \times\left(1-\exp \left(-0.03 \rho_{A}\right)\right)+0.0016 \\
& \times \rho_{A}+7.9 \\
h\left(P, \rho_{A}\right)= & \left(0.088+6.77 \times 10^{-4} \times \rho_{A}\right) \times P^{2}+2.85 \\
& \times 10^{-4} \times \rho_{A}+0.557
\end{aligned}
$$

where $P$ is the contact pressure and $\rho_{A}$ is the area density of lubricant. Equation (2) is used when the contact pressure is higher than $5 \mathrm{MPa}$ under the dry condition or greater than $3 \mathrm{MPa}$ under the lubricated condition. At low contact pressure conditions, equation (3) should be used to calculate the IHTC.

\subsection{Effect of contact pressure on IHTC}

Figure 2 displays the experimental and modelling results under dry and lubricated conditions, showing the effect of contact pressure on IHTC. Under the dry condition, the IHTC increases considerably from $0.1 \mathrm{~kW} / \mathrm{m}^{2} \mathrm{~K}$ to approximately $11 \mathrm{~kW} / \mathrm{m}^{2} \mathrm{~K}$ when the contact pressure increases from 0 to $13 \mathrm{MPa}$, followed by a gentle increase as the contact pressure increases from 13 to $20 \mathrm{MPa}$. When the contact pressure is higher than $20 \mathrm{MPa}$, a plateau of the IHTC value is observed, at a value of approximately $12.3 \mathrm{~kW} / \mathrm{m}^{2} \mathrm{~K}$, showing an almost doubled value compared to that of high strength steel [11]. As such, the quenching time required for the hot stamping of aluminium alloys is expected to be much shorter than that required for steels. The real contact area between the workpiece and die is usually much less than the apparent contact area and the real contact area increases with the contact 


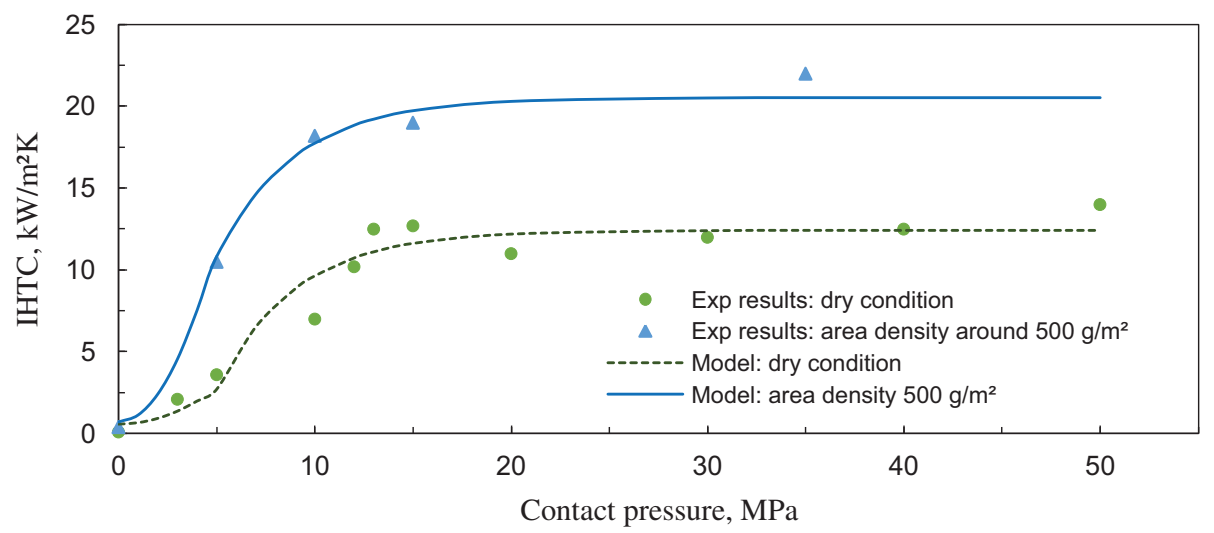

Figure 2. Effect of contact pressure on the IHTC at both dry and lubricated conditions.

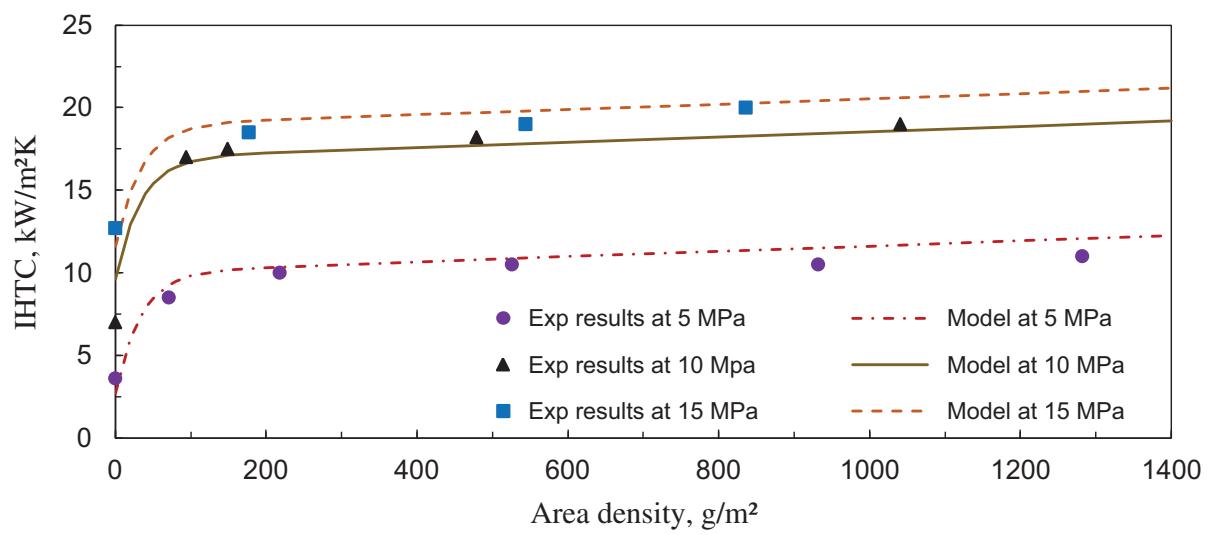

Figure 3. Effect of area density of lubricant (Omega-35) on IHTC at 5, 10 and $15 \mathrm{MPa}$.

pressure due to the elastic and plastic deformations of the asperities [19]. The increased real contact area would be beneficial to the interfacial heat transfer from the workpiece to the tooling, leading to the increasing IHTC value with increasing contact pressure. A large contact area ratio (real contact area to apparent contact area ratio) might be the reason for the IHTC value plateau.

When the lubricant (Omega-35) was applied onto the tool surface, the overall evolution of the IHTC follows a similar trend to that of the dry condition, i.e. a sharp increase at the initial stage, followed by a plateau at high contact pressures. When the area density of lubricant was $500 \mathrm{~g} / \mathrm{m}^{2}$, the IHTC increased dramatically from $0.4 \mathrm{~kW} / \mathrm{m}^{2} \mathrm{~K}$ at $0 \mathrm{MPa}$ to $19.7 \mathrm{~kW} / \mathrm{m}^{2} \mathrm{~K}$ at $15 \mathrm{MPa}$. When the contact pressure reached $20 \mathrm{MPa}$, the IHTC converged to a value of $20.4 \mathrm{~kW} / \mathrm{m}^{2} \mathrm{~K}$. However, the application of Omega-35 increased the peak IHTC values by approximately $60 \%$, compared to the dry condition. The thermal conductivity of Omega-35 is $1.3 \mathrm{~W} / \mathrm{m} \mathrm{K}$, which is higher than that of air $(0.0271 \mathrm{~W} / \mathrm{m} \mathrm{K})$, thus the heat flow is much more rapid when lubricant fills up the vacancies of the asperities at the contact interface. This is one of the reasons for the higher IHTC values under lubricated conditions. On the other hand, the volatile ingredient within the Omega-35 could have also contributed to the rapid dissipation of heat.
Compared with previous research, the present result also showed an obvious plateau but the convergence points, $15 \mathrm{MPa}$ at both dry and lubricated conditions, were much lower than the results by Bai et al. (the transient pressure was $200 \mathrm{MPa}$ [6]) and Yukawa et al. (the transient pressure was $300 \mathrm{MPa}$ [14]), which is caused by the lower strength of aluminium alloys at elevated temperatures. This feature would be favourable for the industrial application of the hot stamping process for aluminium alloys, because a lower forming press capacity would be required and a longer tool life would be expected.

\subsection{Effect of area density of lubricant on IHTC}

Figure 3 shows the effect of area density of lubricant on the IHTC. The evolutions of the IHTC were determined as a function of lubricant thickness, expressed as the area density of lubricant, at different contact pressures. The same trend can be observed at different contact pressures, i.e. as the lubricant layer thickness increases, a steep followed by a gentle increase in the IHTC values was observed. The IHTC value is larger when more lubricant fills up the vacancies between the workpiece and die at high pressures. The transient point was found at $100 \mathrm{~g} / \mathrm{m}^{2}$, although the contact pressures are different, indicating that this amount of lubricant may have 
just filled the vacancies of the asperities, increasing the real contact area correspondingly. The IHTC then slowly ramped up linearly with area density, at an increasing rate of $0.0016 \mathrm{~kW} / \mathrm{m}^{2} \mathrm{~K}$ per $1 \mathrm{~g} / \mathrm{m}^{2}$.

\section{Conclusion}

Experiments have been performed to study the effect of contact pressure and area density of lubricant on the IHTC between the contact surfaces of a hot AA7075 workpiece and cold dies in a hot stamping operation. The temperature histories at specific locations in the workpiece were measured and compared with simulated results from the FE model. The IHTC values were therefore determined.

It was found that IHTC increased with contact pressure and remained stable at $12.3 \mathrm{~kW} / \mathrm{m}^{2} \mathrm{~K}$ under the dry condition. Under the lubricated condition using Omega-35, the IHTC was always larger than that of the dry condition at the same contact pressure, and the values converged to about $20.3 \mathrm{~kW} / \mathrm{m}^{2} \mathrm{~K}$ at $20 \mathrm{MPa}$. The application of Omega-35 as a lubricant for the hot stamping process was found to be beneficial. A model to calculate IHTC value as a function of pressure and area density of lubricant was also developed.

\section{References}

1. H. Karbasian, A.E. Tekkaya, J. Mater. Process. Technol. 210 (2010) 2103-2118.

2. O. El Fakir, L. Wang, D. Balint, J.P. Dear, J. Lin, T.A. Dean, Int. J. Mach. Tools Manuf. 87 (2014) 39-48.
3. M. Raugei, O. El Fakir, L. Wang, J. Lin, D. Morrey, J. Clean. Prod. 83 (2014) 80-86.

4. O. El Fakir, L. Wang, D. Balint, J.P. Dear, J. Lin, Procedia Eng. 81 (2014) 736-741.

5. L. Wang, M. Strangwood, D. Balint, J. Lin, T.A. Dean, Mater. Sci. Eng. A 528 (2011) 2648-2656.

6. Q. Bai, J. Lin, L. Zhan, T.A. Dean, D.S. Balint, Z. Zhang, Int. J. Mach. Tools Manuf. 56 (2012) 102-110.

7. V.K. Jain, J. Mater. Shap. Technol. 8 (1990) 193-202.

8. D.J. Jeong, D.J. Kim, J.H. Kim, B.M. Kim, T.A. Dean, J. Mater. Process. Technol. 113 (2001) 544-550.

9. Z.M. Hu, J.W. Brooks, T.A. Dean, Proc. Inst. Mech. Eng. Part C J. Mech. Eng. Sci. 212 (1998) 485-496.

10. J.M. Lee, I.K. Lee, K.H. Lee, D.S. Kim, B.M. Kim, Trans. Nonferrous Met. Soc. China 22 (2012) s831-s837.

11. P. Hu, L. Ying, Y. Li, Z. Liao, J. Mater. Process. Technol. 213 (2013) 1475-1483.

12. Y. Chang, X. Tang, K. Zhao, P. Hu, Y. Wu, J. Mater. Process. 228 (2016) 25-33.

13. C.C. Chang, A.N. Bramley, Proc. Instn. Mech. Engrs. 216 (2002) 1179-1186.

14. N. Yukawa, Y. Nakashima, T. Ishiguro, E. Abe, T. Ishikawa, T. Choda, Procedia Eng. 81 (2014) 492-497.

15. Z. Malinowski, J.G. Lenard, M.E. Davies, J. Mater. Process. Technol. 41 (1994) 125-142.

16. J.G. Lenard, M.E. Davies, CIRP Ann. - Manuf. Technol. 41 (1992) 307-310.

17. P.R. Burte, Y.T. Im, T. Altan, S.L. Semiatin, J. Manuf. Sci. Eng. 112 (1990) 332-339.

18. K. Ji, O. El Fakir, H. Gao, L. Wang, Mater. Today: Proc. $2 \mathrm{~S}$ (2015) 434-439.

19. B. Buchner, M. Buchner, B. Buchmayr, Tribol. Int. 42 (2009) 897-901.

Cite this article as: Ji K, Liu X, El Fakir O, Liu J, Zhang Q \& Wang L: Determination of the Interfacial Heat Transfer Coefficient in the Hot Stamping of AA7075. Manufacturing Rev. 2016, 3, 16. 